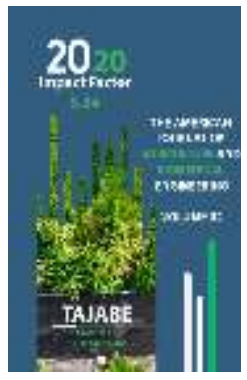

\title{
The Process Of Drying Plums And Taking Precautions In Their Storage
}

\author{
Jamilakhon Mukhammadovna Ermakova \\ Assistant Of The Department Of "Storage, Processing And Packaging Of Agricultural \\ Products", Andijan Institute Of Agriculture And Agrotechnology, Uzbekistan
}

Journal Website:

http://usajournalshub.c

om/index,php/tajabe

Copyright: Original content from this work may be used under the terms of the creative commons attributes 4.0 licence.

\section{ABSTRACT}

The article provides information from the literature on cutting, transportation, sorting, inspection, washing, immersion (blanching), desulfurization, dehumidification, drying and storage of dried plum varieties. In particular, during drying, stoves and ovens must be constructed in a manner that fully meets fire safety requirements. Those who work with caustic soda should also be provided with special gowns, shoes, respirators, goggles and gloves.

\section{KEYWORDS}

Plum, plum varieties, drying area, harvesting, sorting, drying, dry product, sanitary requirements.

\section{INTRODUCTION}

Very good varieties of plums are obtained from the varieties of Samarkand Black Plum, Burton, Arton, Autumn, Hungarian violet, Ispolinskaya, Black Plum, Anna Shpet and Kirke.

Dried plums should be well cooked. Therefore, when the plum is fully ripe, its sugar content, acidity and other substances reach the appropriate level.

Methods of timely and correct harvesting, transportation and preparation for drying mean obtaining a quality dry product. Harvest is interrupted only on dry and open days. 
The American Journal of Agriculture and Boimedical Engineering (ISSN - 2689-1018)

Published: October 31, 2020 | Pages: 81-86

\section{THE MAIN FINDINGS AND RESULTS}

If prunes are plucked during pruning, their skin will be damaged and spots will appear on them. In damaged fruits microbiological processes begin, the juice flows, the dry matter is significantly reduced. It is therefore not recommended to crush the fruit. Only manual collection is required. Hand-picked fruits are carefully placed in special baskets or boxes.
Spills on the ground are collected before cutting. The fruits are cut first on the lower and then on the upper branches of the tree. Various ladders are used to cut the crop of tall branches. Plums are put in baskets or boxes. They are then carefully transported and brought to the drying area.

Table 1

Evaluation of the amount of sugar and acid in plums and dry matter

\begin{tabular}{|r|c|c|c|c|}
\hline \multirow{2}{*}{ No } & Plum varieties & The amount & The amount & Dry product \\
& & of sugar in & of acid in & evaluation \\
& & wet fruit (\%) & wet fruit (\%) & (балn) \\
\hline 1 & Burton & $11,5-14,5$ & $0,6-1,2$ & $4-5$ \\
\hline 3 & Hungarian violet & 52,9 & 2,34 & 4 \\
\hline 4 & Black cherry & 14,3 & 1,32 & 4 \\
\hline 5 & Kamarkand black & 12,9 & 0,96 & 4,8 \\
\hline & plum & 15,4 & 1,3 & \\
\hline
\end{tabular}

Plums are collected in boxes of $16 \mathrm{~kg}$. The crop is transported in trucks or wheelchairs.
Harvested plum fruits cannot be stored for more than 24 hours. Therefore, special care should be taken in the timely delivery of plum fruits to the drying point. 
Table 2

\section{The amount of dry product obtained from dried varieties of plums divided into} whole and halved

\begin{tabular}{|r|c|c|c|}
\hline \multirow{2}{*}{ № } & Plum varieties & Dry product & Dry product \\
& & output (whole), & output (divided \\
into two),
\end{tabular}

In addition to sorting the raw materials, those that are not at the same time conditioned (rotten, crushed, damaged by disease or insects) are separated. Depending on the size, color, degree of maturity, the selected raw materials are then divided into varieties.

All kinds of weeds, sand, microorganisms, as well as residues of toxins attached to the plum fruit are washed away.

Production technology includes cutting, transportation, storage, sorting, inspection, washing, and immersion in an alkaline solution - blanching, sulfur smoking, drying, moisture equalization, packaging and storage.
Shelters will be built in the drying area for reception, temporary storage, sorting, and placement on trays. The shed should also have tables, scales, a barrel and a pot. There will also be smoking chambers in the drying area

and warehouses for temporary storage of the finished dry product.

The smoking chambers consist of two chambers with a length of $3.5 \mathrm{m3}$, a width of 3.5 $\mathrm{m}$ and a height of $2.5 \mathrm{~m}$, with a volume of 27-30 m3. Boxes can also be used for smoking. The smoking box is made of plywood with a length of $105-110 \mathrm{~cm}$, width $105-110 \mathrm{~cm}$ and height $95-$ $110 \mathrm{~cm}$. 
Fruits brought to the drying area are washed, cleaned, cut in half, blanched and smoked with sulfur.

Variation of plum fruits depending on how ripe, color, shape, size - is called sorting. This helps to avoid crushing the raw material processed (blanched) in the alkaline solution, to select the correct concentration of the solution and with it to separate the fruit from the skin, as well as to properly smoke with sulfur.

Stoves are built to immerse the fruits in a boiling alkaline solution, and 2 cast iron pots are installed in each of them. These boilers are used alternately.

Safety rules are as follows: put a basket of fruit in the pot and pour a certain amount of clean water into the pot and boil it so that water does not spill during boiling. Blanching and sulfitization require strict adherence to sanitary requirements and safety regulations. Accidents at fruit drying points should be prevented.

Stoves and ovens must be constructed in a manner that fully meets fire safety requirements. Workers working with caustic soda should be provided with special gowns and footwear, respirators, goggles and gloves. Eating and smoking are prohibited in the workplace. Before eating, take off work clothes, wash hands, face thoroughly, and rinse mouth.

The quality of the dry product depends in many ways on the raw material. It is advisable to dry only fruits that meet the standard requirements. Fruits should not rot, do not rot, have all the necessary substances in them, especially the acidity and sugar content should be sufficient.

Peeling of plum fruits is done in order to separate the unwanted part of the raw material and improve the color of the dry product. Peeled fruit dries much faster. As a result of the shortening of the drying time, more sugar, acid, vitamins and other substances are stored in the dry product.

Plum fruits are divided into varieties depending on their size on calibration machines. Plums can be divided into 3-4 varieties, depending on their size. It is then inspected, i.e. rotten, crushed, overcooked and raw. Sorting according to quality is of great importance in alkali immersion and drying.

Depending on the quality, the sorting is done on conveyor belts or rollers or on the table. The fruits are then washed and immersed in a solution of caustic soda. This work is carried out in a blancher or in a boiler with a capacity of 300-350 liters of water. Caustic soda solution is prepared in $0.5 \%$. Each variety of fruit is tested and then the time of immersion in the solution is determined. This time should not exceed 15-30 seconds.

Instead of dipping plums in the solution, you can also heat them in a special machine. The color of plums processed in this way does not change, the quality improves. Fruits soaked in an alkaline solution are slightly the same color. The disadvantage of this method is that the fruit is partially damaged in the machine drum.

Plums prepared in this way are placed on clean trays and placed on the stalks in the drying area, where the sun shines well. After 3-4 days the fruits are rolled up, and after another 5-7 days, after their moisture has escaped considerably, they are placed on stacks and drying is continued in the shade.

Plums are dried for 8-19 days, depending on the size of the fruit. When not separated from the flesh, the fruit is considered completely dried. Such dried plums should not stick together when crushed by hand.

The drying time of plums should be 3-5 days, the drying time should be 10 days, and the final moisture content should be $25 \%$. To equalize the moisture content of the product, it is stored in boxes for 12-16 days. The moisture 
content of dried plums should not exceed $25 \%$. $24-36 \%$ of plum fruit is peeled.

White varieties of plums - "Burton", "Arton" and others - are smoked in sulfur dioxide after blanching or heating. One kilogram of sulfur is consumed per kilogram of fruit. Smoked dried is black or bluish black, and smoked is light yellow or brown.

To lighten the color of plum peel, the finished product is treated in $0.3-0.5 \%$ boiling glycerin solution for 3-5 seconds. It is then dried to standard and sorted and placed in boxes.

Dried plums are packed in special boxes or kraft bags for storage. The mouth is tightly closed and placed on clean dry shelves. The first shelf is $10 \mathrm{~cm}$ above the ground. A $0.5-$ meter path is left between the walls and shelves, and a single central 1.5-1.8-meter side path is left between the rows.

The maximum height of the shelves should be 2.5 meters for the product to be easy to install and remove. The product is divided into batches and varieties on the shelves. Each product batch must have a label. It must contain the name of the product, brand, weight, date of manufacture and acceptance.

On average, $600 \mathrm{~kg}$ of plum peel can be placed in $1 \mathrm{~m} 3$ of space.

The dry product accepted for storage must be thoroughly inspected. Dried products infected with the disease, pests or infested with eggs are not accepted for storage.

Storage rooms should have electric lights, fire extinguishers. Shelves and rooms where the product is stored should be clean and frequently ventilated and dusted, but cleaning floors and walls with wet rags is prohibited.

During storage of dried plums it is necessary to monitor the temperature and relative humidity in the room. To do this, thermometers and psychrometers should be kept at a height of 1.3-1.5 meters in the room. For storage of dried plums it is desirable to keep the temperature up to $+10-120 \mathrm{C}$ and relative humidity $65-70 \%$.

If the fruits are over-dried, the product will be of poor quality and will be reduced. Insufficiently dried fruits spoil quickly and are not suitable for storage. Therefore, the finished product should be removed from the drying area in a timely manner. It is determined by capturing in the morning that the plum peel is ready.

A well-dried fruit cannot be stored for a long time because it quickly molds and rots, which leads to a decrease in its consumer value. Very dry fruits become dull in color, spoil the taste, reduce vitamins. The dried product is stored for 10-12 days so that the humidity is the same. After this period, the dried fruits are sorted according to quality, cleaned of various impurities and placed in containers for protection from pests.

\section{CONCLUSION}

In the drying of varieties intended for drying plums, in addition to the drying technology, it is necessary to take precautions during the drying process. The purpose is to obtain a quality dry product and to supply the obtained dry product for human consumption throughout the year without destroying it. Drying of wet fruits is carried out using the technological methods that have come down to us from ancient times. Currently, drying methods based on modern technologies are also developing rapidly. However, due to the high demand for environmentally friendly products, natural drying of plums is much better and more profitable than artificial drying. Storage of dried plums should be carried out in accordance with the rules of storage.

This article is about picking, transporting, sorting, inspecting, washing, dipping (blanching) plums, sulfur smoking, moisture leveling, drying and storage of dried plum varieties. On this basis, along with the 
development of exports of dry products in the country, it can achieve a number of positive achievements in the field of agriculture. In particular, the loading and unloading and storage of dry products is very convenient, while dry products are also an invaluable quality product for various expeditions and passengers.

\section{REFERENCES}

1. Shoumarov X.B., Islamov S.Ya. (2011) Technology of storage and primary processing of agricultural products. Tashkent.

2. R.Oripov, I.Sulaymonov, E.Umurzakov. (1991) "Technology of storage and processing of agricultural products". Tashkent. "Mehnat".

3. MM Mirzaev, VV Kuznetsov. (1983) "Pomology of Uzbekistan". Uzbekistan.

4. H.Buriev, R.Rizaev. (1966) "Biochemistry and technology of fruit and grape products." Tashkent.

5. X. Bo'riev, R. Jo'raev, O. Alimov. (2002) "Storage and primary processing of fruits and vegetables." Tashkent.

6. Shirokov E.P. (1989) Workshop on storage and processing of fruits and vegetables. Moscow. Kolos.

7. R.J. Juraev, M.M. Adilov. (1999) "Technology of storage and processing of agricultural products." - Tashkent.

8. E.P. Shirokov, V.I. Polegaev Technology of storage and processing of crop products and the basics of standardization.

9. Rybakov A.A., Ostrouxova S.A. (1981) Fruit growing in Uzbekistan. - Tashkent. "Teacher".

10. Ostonakulov T.E., Narzieva $X$. and B.Gulamov. (2011) "Fundamentals of Fruit Growing”. - Tashkent.

11. www. ziyo-net. ru 